\title{
APPLICATION OF QUALITY MANAGEMENT IN BUSINESS PRACTICE IN THE CONTEXT OF INDUSTRY 4.0
}

\author{
${ }^{1}$ Martin MAREČEK-KOLIBISKÝ, ${ }^{2}$ Marta KUČEROVÁ \\ ${ }^{1,2}$ Slovak University of Technology in Bratislava, Faculty of Materials Science and Technology in Trnava, \\ Slovakia,EU, martin.marecek-kolibisky@stuba.sk, marta.kucerova@stuba.sk
}

https://doi.org/10.37904/metal.2021.4280

\begin{abstract}
In connection with the application of technologies / principles of Industry 4.0, industrial practice also requires a more consistent application of the principles or principles of quality management. This applies to all areas of industry, but it is most pronounced in the automotive industry, engineering industry, metallurgical industry, metallurgy, chemical industry, electrical industry, etc.

The paper focuses on the current requirements of quality management in industrial practice, including metallurgy and materials engineering. High quality requirements in the field of metallurgy are inevitable, as iron, steel and cast iron products are used in many areas of industrial production, but especially in engineering, respectively. automotive industry. Growing competition in the market and increasing customer requirements in today's society are forcing companies to apply the principles of quality management more rigorously. Quality management ensures the quality of products and requirements for the products in the field of metallurgy and materials engineering. New technologies make it possible to improve the production process, participate in research into the properties of materials and quality management serves as a set of coordinated activities related to quality in the context of the functioning of the entire company. In industry 4.0, products made of iron, steel, cast iron and also plastics, in line with technological advances in IT and electrical engineering, will be increasingly used to develop and improve industrial production. Introduction of elements, resp. Technology 4.0 in connection with the increasing demands on the quality of products and materials also requires changes in the functioning of industrial enterprises and significantly affects the management of human resources.
\end{abstract}

Keywords: Metallurgy, quality management, material engineering, Industry 4.0.

\section{INTRODUCTION}

New technologies bring a new era of business, new approaches to the operation of companies, as well as new jobs that filter new competencies and skills of employees. While new jobs will require new knowledge and new skills, the right combination of skills needed to perform in modern industrial enterprises is increasingly complex and will continue to evolve with the development of a technologically advanced work environment. This will require the next generations of workers to develop their digital skills and build access to lifelong learning. More challenging automation tasks so far include problem-solving skills, intuition, creativity, and persuasion [1].

With the advent of technologies and elements of Industry 4.0 comes the transformation of industry into a digital environment. This transformation affects almost all areas of industry, but it is most pronounced in the automotive industry, engineering industry, metallurgical industry, metallurgy, chemical industry, electrical industry, etc. By applying these technologies and elements of Industry 4.0, an industrial practice also requires a more consistent application of the principles, as principles of quality management. More consistent application of quality management will be based on customer requirements, which will determine competitiveness. The application and continuous improvement of production processes and the entire production system in industrial enterprises will certainly continue to be an essential part of business practice. 


\section{IMPROVING PROCESSES OF QUALITY MANAGEMENT}

The essence of quality management is a process approach or process management, on which the quality management system built according to the international ISO 9000 series standards is based. One of the basic principles of quality management is continuous improvement, which is the integration of other principles, including customer focus, leadership, employee involvement, evidence-based decision making, and relationship management. For effective and efficient quality management in an industrial enterprise, continuous improvement of all activities must be applied/processes and at all levels. However, the key role is played by the main processes, i.e., production/implementation processes that add value to the product.

The starting point for the improvement of production processes and two production systems of the company is the optimal setting and use of production factors. Factors that mean the need to meet all customer requirements and adapt to the changing and conditioned environment of the company (e.g. increased competitiveness, pressure on costs, or increasing flexibility of the company) are important. The aim of these business activities is to achieve measurable economic and production results, such as the efficiency of the production process and timely performance of tasks, as well as identification of factors affecting not only product quality but also shortening inter-operational times, minimizing inventory. Modern methods of industrial engineering and management of production processes in the company acquire an important role in the improvement of existing production systems and the elimination of missing ones [2].

Process management in an industrial enterprise is manifested/applied not only at the level of production but also in logistics, customer service, etc. All these processes and activities must be coherent and coordinated at a high level in order for the company to be efficient in production or services. Some processes and their management are taken care of by artificial intelligence thanks to the advent of Industry 4.0. All processes in business practice are measurable and analyzed with technologies and elements of Industry 4.0 in real-time. Processes can be measured using indicators such as productivity indicators (e.g. OEE), economic (e.g. profit, cost, profitability), qualitative (e.g. FPY, complaints, scrap), time (e.g., tact time, cycle time). These indicators are analyzed in companies using various methodologies, methods, tools, techniques of industrial engineering, and quality management. At present, a number of different methods and tools are described in the scientific literature, which is used in improving processes in business practice, e.g. simple quality management tools (e.g. 7 basic quality tools), various statistical methods, value flow mapping, SMED, TPM, TOC bottleneck theory, lean tools and methods, Six Sigma and more. In fact, it is worth mentioning which of these tools will be effective even in conjunction with the technologies and elements of Industry 4.0. The Industry 4.0 paradigm says that machines will be interconnected, "cloud solutions" will be used, and the process will be constantly optimized in the "digitaltwin" environment. Some methods and tools e.g. (SPC - Statistical Process Control) will be part of the machine and there will be self-regulation resp. for self-optimization. Therefore, it is assumed that in the future, quality will have to move towards predictive analyzes $[3,4,5]$.

The Industry 4.0 paradigm is characterized by interactions and communication between industrial equipment and cyber-physical systems to control processes and activities in real-time. Such cyber-physical systems are e.g. internet of things, artificial intelligence, robotics, cybersecurity, and 3D printing. Through Industry 4.0, companies can leverage autonomous manufacturing systems, make decentralized decisions, and facilitate interconnection and communication between employees, machines, orders, suppliers, and customers. Industry 4.0 based technology and features (as 3D printing) enable businesses to create products that meet customer needs and make it easier to control production parameters such as energy consumption, material flow, and real-time monitoring, increasing their competitiveness $[6,7,8,9]$.

Industry 4.0 is characterized by mutual cooperation, interconnection, and communication of several systems (machines, devices, sensors, and people, transparency of information and virtualization, technical assistance). In other words, machine-to-machine, human-to-machine cooperation, i.e. the ability of systems to support people in decision making and problem-solving and the ability to help people with tasks that are difficult or 
dangerous for them and decentralized decision making, meaning the ability of cyber and physical systems to make simple decisions and become as autonomous as possible [10,11].

Efforts to increase competitiveness are driving research into energy efficiency, reducing emissions, redistributing resources, and intelligent Industry 4.0 equipment in business practice. The growth and spread of Industry 4.0 are related to the implementation of smart factories, smart products, cyber-physics systems, smart cities, and digital sustainability [12,13].

The influence and interconnection of information technologies with machines and robots will change the image of production as we know it today. The implementation of the just-in-time method will significantly prevail, even in production sites where this was not possible. Thanks to these benefits, Industry 4.0 will revive industry in the EU and many companies will move production from Asia back to Europe. Digitization and application of technologies and elements of Industry 4.0 will enable increased production of products to order to individual customers, and increased emphasis will be placed on the required quality of products. It is precisely this fact that it can be stated that methodologies and methods of industrial engineering and quality management will be more promoted, such as TQM and Six Sigma [14].

\section{USE OF INDUSTRY 4.0 TECHNOLOGIES IN INDUSTRIAL PRACTICE}

As part of a research project in which we deal with the impact of Industry 4.0 on the priorities of sustainable human resources management, we dealt with areas, technologies, or elements of Industry 4.0 that businesses use. We also investigated how the implementation of the technologies and elements has currently affected the operation of the company. We focused on the following five industries: automotive industry, engineering industry, metallurgical industry, chemical industry, electrotechnical industry.

From the examined group of companies that participated in the research, we selected a sample of 137 respondents who identified their industries like automotive, engineering, electrotechnical, metallurgical, and chemical industries. The representation of respondents from individual industries is shown in the Table $\mathbf{1}$ and graphically illustrated in Figure 1.

Table 1 Companies structure

\begin{tabular}{|l|l|}
\hline Industry & $\begin{array}{l}\text { Number of } \\
\text { enterprises }\end{array}$ \\
\hline automotive & 65 \\
\hline engineering & 35 \\
\hline electrotechnical & 19 \\
\hline metallurgical & 11 \\
\hline chemical & 7 \\
\hline
\end{tabular}

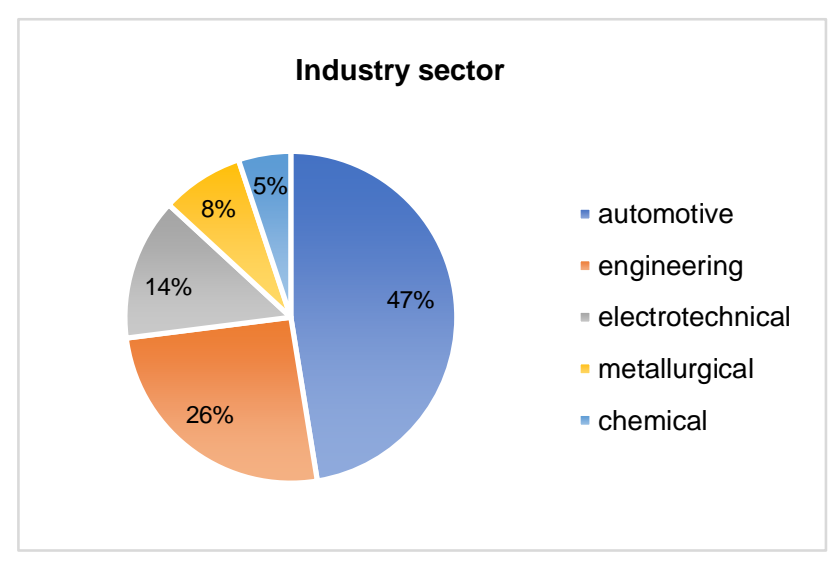

Figure 1 Representation of industries in the survey

The largest number of respondents was from the automotive industry and the engineering industry due to the fact that a large number of companies are focused on these two sectors in Slovakia. At the same time, companies operating in the automotive and engineering industries are leading companies in the introduction of technologies and elements of Industry 4.0.

In this paper, we focused on the use of Industry 4.0 technologies in the researched industrial enterprises. Respondents to the question "Which of the elements of Industry 4.0 do you use in your company" had the opportunity to choose more options. The obtained data are processed in graphical form in Figure 2. 


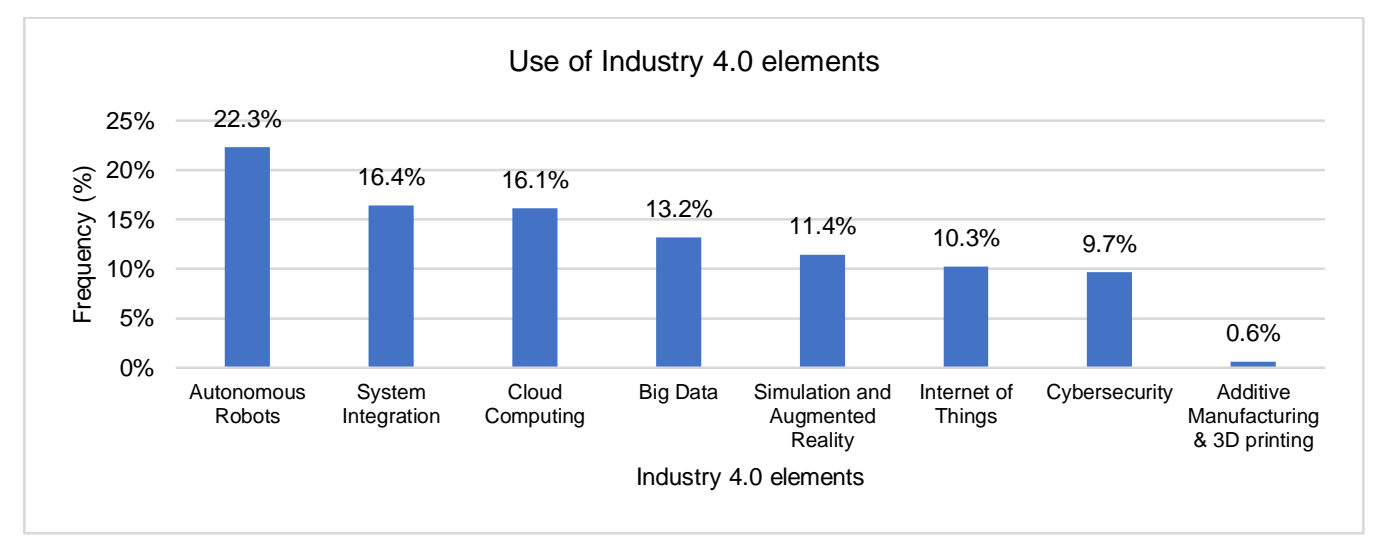

Figure 2 Use of Industry 4.0 elements in industrial practice

The most used area of Industry 4.0 is Autonomous Robots, which are used mainly in automotive and engineering production, which was stated by $22.3 \%$ of respondents. They play a significant role in the main production processes, adding value to the product. Autonomous Robots are elements of human-machine cooperation, this cooperation is once again associated with the Industry 4.0 paradigm. Some autonomous robots replace people in the production process, giving a place for employees in companies to apply analytical and statistical methods to improve the production processes.

Other elements or technologies of Industry 4.0, which, according to the respondents, are used in industrial enterprises, are System Integration and Cloud Computing. These elements enable real-time data sharing, subsequent analysis, and application of methods and tools of industrial engineering and quality management. Real-time data sharing is a combination of data from production, production processes, machines, measuring devices and is combined with external data (administrative claiming, feedback, etc.) and data on energy intensity in production and other measurable quantities that occur in the production process. All these data are used to streamline production, to improve the quality of products and services. The use of Additive Manufacturing \& 3D printing has great potential, but our survey shows that the use of Additive Manufacturing \& 3D printing in business practice was reported by only $0.6 \%$ of respondents. The reason for the low use of Additive Manufacturing \& $3 \mathrm{D}$ printing technology may be the fact that companies currently do not have software, or qualified staff to perform 3D printing.

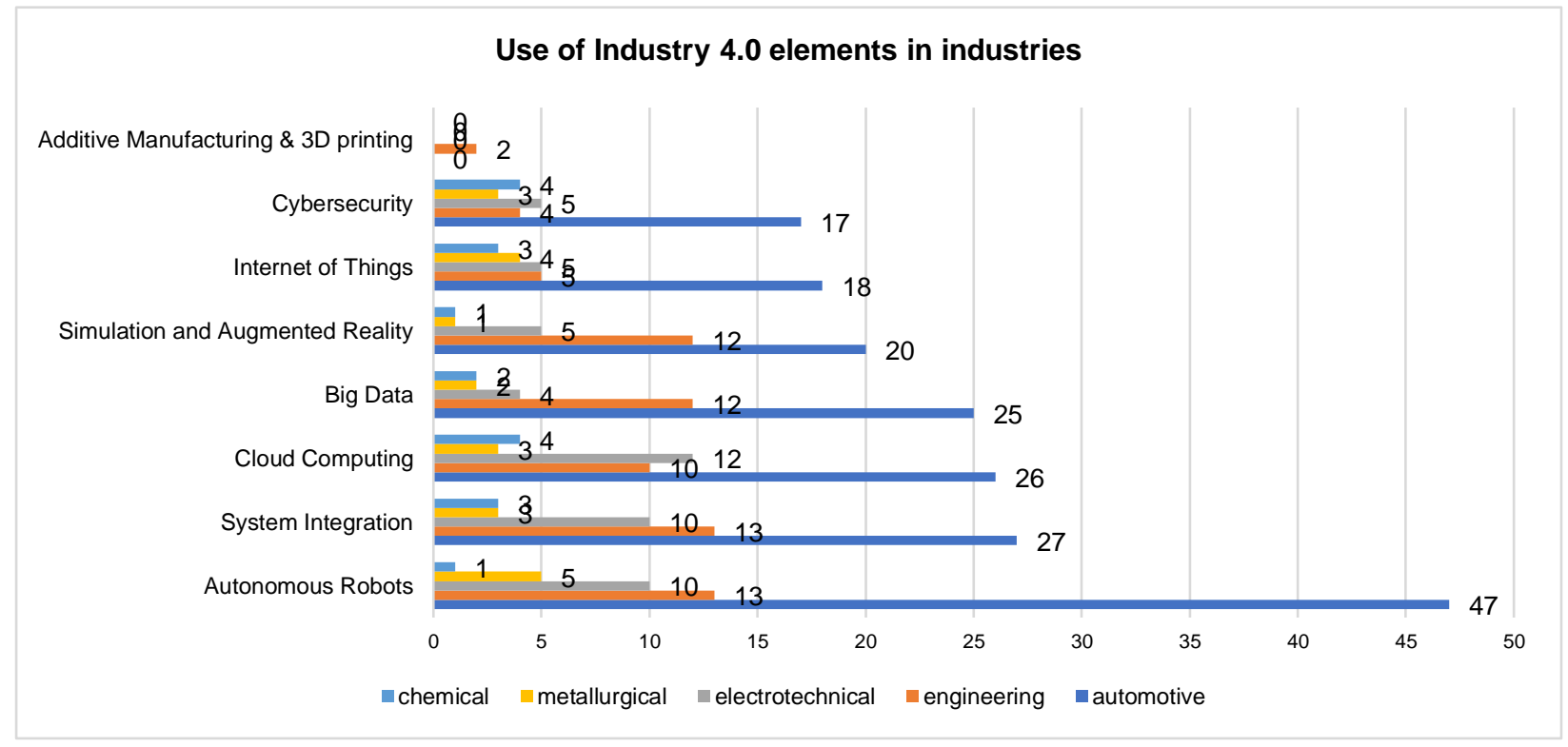

Figure 3 Use of Industry 4.0 elements in industries 
Based on the obtained data, we also tried to evaluate the independent use of Industry 4.0 technologies in the surveyed companies from individual industries. Figure $\mathbf{3}$ is graphically interpreting the application of basic technologies (Autonomous Robots, System Integration, Cloud Computing, Big Data, Simulation and Augmented Reality, Internet of Things, Cybersecurity, Additive Manufacturing \& 3D printing) in individual industries.

The research found that almost all elements of Industry 4.0 are currently applied in automotive companies, except 3D printing.

For comparison, in the companies of the engineering and electrical engineering industry in the areas of Industry 4.0 (Autonomous Robots, System Integration, Cloud Computing, Internet of Things and Cybersecurity) the use of these technologies is relatively balanced. However, it is necessary to take into account the different number of surveyed companies, on 16 respondents from the engineering industry participated in the survey more than from the electrical engineering industry.

As part of the research, we also investigated the impact of elements and technologies of Industry 4.0 on the performance of companies, or what is the current situation in the surveyed companies. To the question "In your opinion, how did the implementation of elements and technologies of Industry 4.0 affect the functioning of the company?" respondents had the opportunity to choose one of the following answers:

After the introduction of the elements of Industry 4.0 company:

- achieves better productivity and results,

- achieves the same productivity and results,

- achieves lower productivity and results,

- the company received sufficient support from the state and the government of the Slovak Republic,

- the company has existential problems,

- $\quad$ other: the company does not have effectively implemented elements of Industry 4.0.

The obtained data are processed in graphical form in Figure 4.

Almost $73 \%$ of respondents described the answer "the company achieves better productivity and results", which can be assessed as a positive fact of the implementation of Industry 4.0 elements in industrial practice.

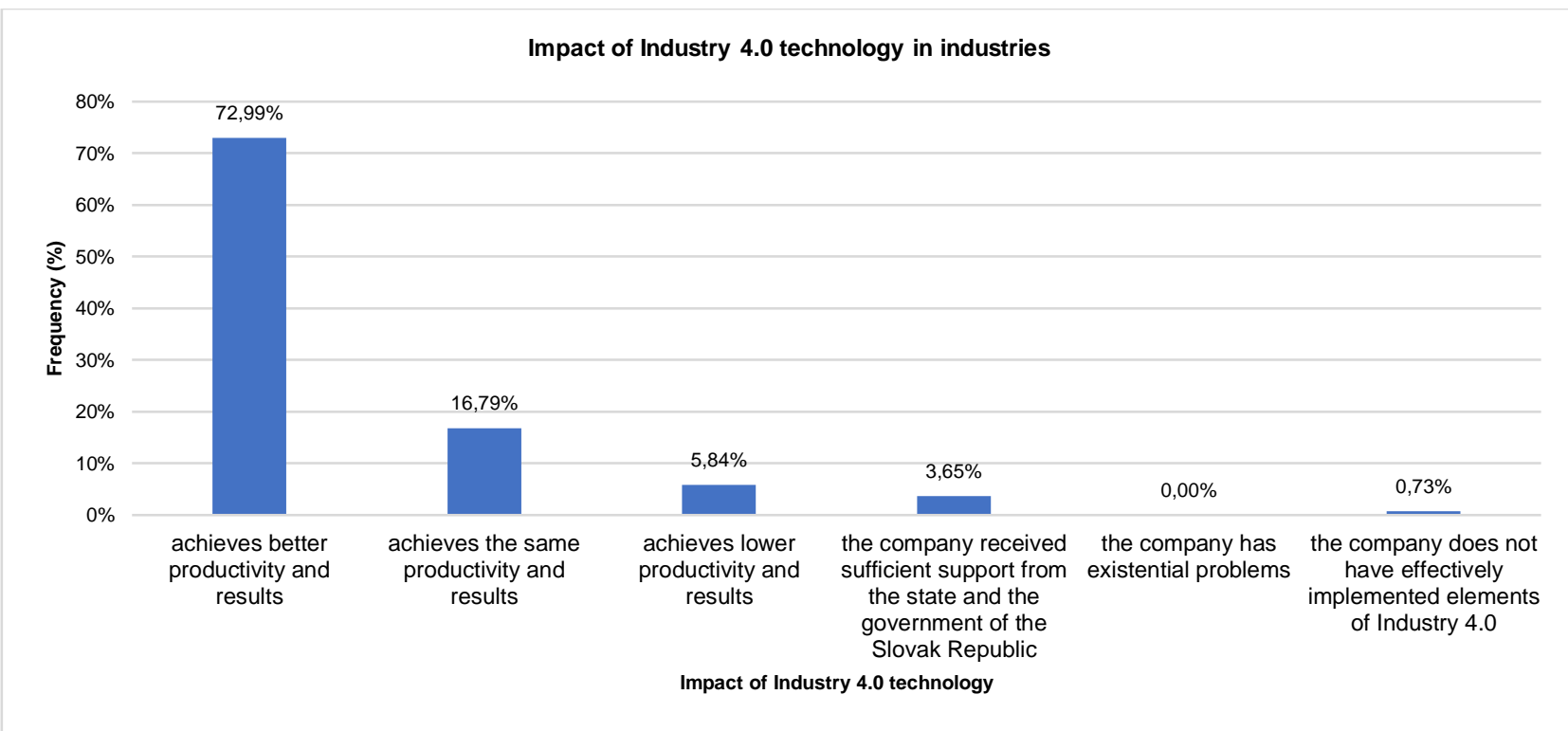

Figure 4 Impact of Industry 4.0 technology in industries 


\section{CONCLUSION}

In the last decade, technology and technological progress have grown exponentially. Mankind, science, and industry know the technologies that have undoubtedly made everyday life easier. Technological progress is still advancing and we cannot realistically imagine at present what awaits us in the industry in the future, but the application of the Industry 4.0 paradigm can certainly be expected. The Industry 4.0 concept is adopted by companies and implemented individual technologies. These technologies are mostly used in the automotive, engineering, electrical, metallurgical, and chemical industries in the automation of production. Due to our research, autonomous robots are mainly used in the mentioned industries, which cooperate with humans in the production process, speed up and automate the production process.

In the context of quality management, it can be stated that the application of elements and technologies of Industry 4.0 is in accordance with the basic principles of quality management. In industrial enterprises, all processes must be constantly improved using the latest technologies. Top management plays a key role here and all employees must be involved in these activities.

\section{ACKNOWLEDGEMENTS}

The paper is part of the solution of the project VEGA 1/0721/20 "Identification of priorities of sustainable human resources management with regard to disadvantaged employees in the context of Industry 4.0".

\section{REFERENCES}

[1] FREY, C.B., OSBORNE, M.A. The future of employment: How susceptible are jobs to computerisation? [online]. 2013. [viewed: 2020-04-26]. Available from: https://www.oxfordmartin.ox.ac.uk/downloads/academic/futureofemployment.pdf.

[2] DARON, M., GÓRSKA, M., DUNAY, A. Improvement of the production system functioning with using quality management tools in the metallurgical enterprise. In: MATEC Web of Conferences. 2018, vol. 183, pp. 1-6.

[3] GAJDZIK, B. World Class Manufacturing in metallurgical enterprise. Metalurgija. 2013, vol. 52, pp. $131-134$.

[4] PAULOVÁ, I. Komplexné manažérstvo kvality. Bratislava: Iura Edition, 2013.

[5] IPA Slovakia. Kvalita a Industry 4.0. [online]. 2017. [viewed: 2020-04-24]. Available from: https://www.ipaslovakia.sk/clanok/kvalita-a-industry-4-0.

[6] SHROUF, F., ORDIERES, J., MIRAGLIOTTA, G. Smart factories in Industry 4.0: A review of the concept and of energy management approached in production based on the Internet of Things paradigm. In: IEEE Int. Conf. Ind. Eng. Eng. Manag. 2014, pp. 697-701.

[7] XU, L.D., XU, E.L., LI, L. Industry 4.0: State of the art and future trends. Int. J. Prod. Res. 2018. vol. 56, pp. 29412962.

[8] LASI, H., FETTKE, P., KEMPER, H.G., FELD, T., HOFMANN, M. 2014. Industry 4.0. Bus. Inf. Syst. Eng. 2014, vol. 6, pp. 239-242.

[9] HERNANDEZ KORNER, M.E., LAMBÁN, M.P., Albajez, J.A., SANTOLARIA, J., CORRALES, L., ROYO, J. Systematic Literature Review: Integration of Additive Manufacturing and Industry 4.0. Metals. 2020, vol. 10.

[10] European Union. Industry 4.0. [online]. 2015. [viewed: 2020-04-29]. Available from: https://www.europarl.europa.eu/RegData/etudes/BRIE/2015/568337/EPRS BRI(2015)568337 EN.pdf

[11] KRUPITZER, C., LESCH, V., ZÜFLE, M., KOUNEV, S., MÜLLER, S., EDINGER, J., BECKER, C., LEMKEN, A., SCHÄFER, D. A Survey on Human Machine Interaction in Industry 4.0. 2020, vol. 1, pp. 45.

[12] ROBLEK, V., MEŠKO, M., KRAPEŽ, A. A Complex View of Industry 4.0. Sage Open, 2016, vol. 6.

[13] ROMERO, D.; STAHRE, J.; TAISCH, M. 2020. The Operator 4.0: Towards socially sustainable factories of the future. Computers and Industrial Engineering. 2020, vol. 139, pp. $105-112$.

[14] Goodwill. Priemysel 4.0 a Slovensko ako sa udržat' medzi elitou. [online]. 2016. [viewed: 2020-04-26]. Available from: http://www.goodwill.eu.sk/clanky/item/75-priemysel-4-0-a-slovensko-ako-sa-udrzat-medzi-elitou 